\title{
Thermal contribution of serpentinization to temperature variations in the subsea floor
}

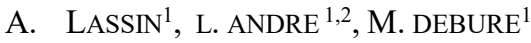

${ }^{1}$ BRGM, Water, Environment, Process Development and Analysis Division, 3 Avenue C. Guillemin, 45060 Orléans, France

${ }^{2}$ ISTO, UMR7327, Université d'Orléans, CNRS, BRGM, 45071 Orléans, France

The serpentinization of the mantle rocks by interaction with pore water is presented as one process that can produce large quantities of brines and, ultimately of salt rocks ${ }^{[1]}$. It is also known to generate an important amount of heat through exothermic hydration with consequences on the temperature of the water-rock system. In turn, this can have consequences on the venting of hydrothermal systems, and on the kinetics of reactions ${ }^{[2]}$. Another expected consequence is the increase of the salt solubility and therefore the possibility to increase the pore water salinity. The objective of this work is to investigate this process according to a geochemical modelling approach.

Calculations are done on a Representative Elementary Volume $\left(1 \mathrm{~m}^{3}\right)$ composed of enstatite and characterized by $10 \%$ porosity fully saturated with saline water. The geochemical model considers the serpentinization process resulting from the reaction of enstatite with the saline pore solution. A sensitivity analysis is done according to the initial temperature $\left(100,150\right.$ and $\left.200^{\circ} \mathrm{C}\right)$, the water composition and the ratio of reacted enstatite ${ }^{[1]}$. The results are interpreted in terms of temperature variations of the system given the heat capacity of primary and secondary minerals and of the saline solution. For the latter, heat capacity is computed with the geochemical code PhreeSCALE [3] which is also used to follow the evolution of the water composition and the saturation indexes of the relevant salts. The temperature impact on these processes is the key factor to investigate.

[1] Debure M., Lassin A., Marty N., Claret F., Virgone A., Calassou S., Gaucher E.C. (2019). Thermodynamic evidence of giant salt deposit formation by serpentinization: an alternative mechanism to solar evaporation. Sci. Reports, 9, 11720 .

[2] Lowel R.P., Rona P.A. (2002). Seafloor hydrothermal systems driven by the serprentinization of peridotites.

${ }^{[3]}$ Lach et al. (2016) - Thermal and Volumetric Properties of Complex Aqueous Electrolyte Solutions Using the Pitzer Formalism - The PhreeSCALE Code. Comput. Geosci, 92, 58-69. 